Case report:

\title{
Preservation of Lingual Nerve In Excision Of Bilateral Submandibular Sialolith Via Intraoral Approach: A Case Report
}

\author{
Nasir MSNM $M^{1}$, Ibrahim $R^{2}$, Abdullah $B^{3}$
}

\begin{abstract}
$\underline{\text { Abstract }}$
Salivary gland stone (sialolithiasis) is most common disease of the salivary gland and mainly occur at the submandibular gland. Traditionally, sialolithiasis is removed via an extra-oral approach but the major disadvantages of this treatment include a risk of injuring the lingul nerve, marginal mandibular nerve and scar formation. In this case report, we revealed an even less invasive intraoral surgical technique for the removal of sialolith that does not affect the submandibular gland function with the preservation of lingual nerve. This report describes a patient who had unusual bilateral submandibular gland sialolith that posteriorly located,which successfully removed via intraoral approach without any postoperative complications.
\end{abstract}

Keywords: Sialolithiasis, submandibular gland, lingual nerve.

International Journal of Human and Health Sciences Vol. 02 No. 03 July'18 Page : 161-163 DOI: http://dx.doi.org/10.31344/ijhhs.v2i3.47

\section{Introduction}

Sialolithiasis is a disease characterised by the development of salivary stones, known as calculi or sialoliths, in the salivary ducts or in the salivary gland themselves. More than $80 \%$ of salivary sialoliths occur in the submandibular gland or in its duct, $6-15 \%$ in the parotid gland and about $2 \%$ in the sublingual and minor salivary gland ${ }^{1-2}$. Its estimated frequency is $1.2 \%$ in the adult population, with a slight male predominance ${ }^{3}$. Flow of saliva against gravity, longer secretory duct, its more alkaline $\mathrm{pH}$ and the high mucin and calcium content could explain the preferential stone formation in the submandibular gland ${ }^{5}$.

One of the important nerve that closely related with submandibular gland and its duct is lingual nerve. It supplies the general sensation to the mucosa of the anterior two-thirds of the tongue, the sublingual mucosa, the mandibular lingual gingiva and the floor of the mouth ${ }^{6-7}$.

In the excision of submandibular gland cases, problems arise due to formation of scar, alteration of dermal sensation, taste formation, also functional problems such as the reduction of salivation. Because of such problems, recently, in the treatment of submandibular duct stones, efforts have been made to preserve the submandibular gland (9-10).

\section{Case Summary}

A 24 year old male presented to our department for the chief complaint of the postprandial swelling at the left submandibular area of neck. This symptom was initiated one years ago and getting increase in size. It was associated with increase in severity of pain and swelling before and during meal followed by gradual relief by itself.

1. Mohd Shaiful Nizam Mamat, Department of Otorhinolaryngology, Hospital Tengku Ampuan Afzan, 25100 Kuantan, Pahang, Malaysia

2. Rohaida Ibrahim, Department of Otorhinolaryngology, Hospital Tengku Ampuan Afzan, 25100 Kuantan, Pahang, Malaysia

3. Baharudin Abdullah, Department of Otorhinolaryngology-Head \& Neck Surgery, School of Medical Sciences, Universiti Sains Malaysia Health Campus, 16150 Kota Bharu, Kelantan, Malaysia

Correspondence to: Mohd Shaiful Nizam bin Mamat Nasir, Department of Otorhinolaryngology-Head \& Neck Surgery, School of Medical Sciences, Universiti Sains Malaysia Health Campus, 16150 Kota Bharu, Kelantan, Malaysia \& Department of Otorhinolaryngology, Hospital Tengku Ampuan Afzan, 25100 Kuantan, Pahang, Malaysia.Email: drshaiful10@gmail.com 
In physical examination, a diffuse swelling was seen on the left submandibular area about $3 \mathrm{~cm}$ $\mathrm{x} 3 \mathrm{~cm}$, slight tenderness but firm in consistency. Surprisingly, in intraoral examination, 2 firm swelling can be felt over both right and left floor of the mouth. Considering the history and physical examination, a provisional diagnosis of submandibular duct stones was made hencecomputed tomography of the neck was performed.

The result showed two rounded opacity likely suggestive of the calculus located at the superomedial to the submandibular gland measuring $1.2 \mathrm{~cm} \times 0.9 \mathrm{~cm}$ on the right side and $0.8 \mathrm{~cm} \times 0.9 \mathrm{~cm}$ on the left side (Figure 1). Other laboratory investigations were within normal limits



Figure 1: CT showed calculus seen at the superomedial to the bilateral submandibular gland (Arrow).

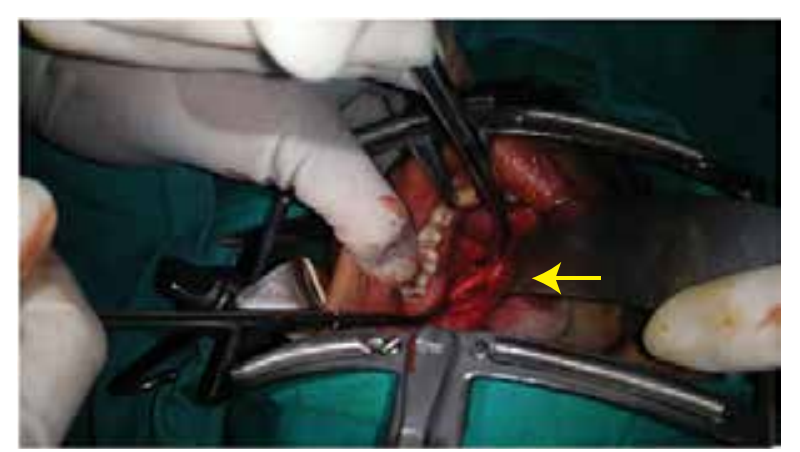

Figure. 2: Lingual nerve identified and preserved. (Arrow)
In view of patient was young and avoidance of external scar, so we planned to remove the stones by intraoral approach to preserve the submandibular gland in general anaesthesia. Intra-operatively two calculi were removed by taking incision at the floor of mouth opposite third lower molar tooth bilaterally. We manage to located and preserved lingual nerve intraoperatively (Figure 2). Post operatively patient made an eventful recovery and was put on our regular outpatient follow up.

\section{Discussion}

Choice of treatment for sialolithiasis is depend on the location and size of calculus. Ideally, intraoral approach is preserved when the sialolith is easily palpable and located in the distal third of the gland. But, in patient with intraglandular calculus and associated with recurrent infection may require submandibular sialoadenectomy ${ }^{13}$.

The intraoral access for the removal of calculus is quite efficient and less harmful

in relation to sialoadenectomy, as gland function is maintained. Advantages of the intraoral approach include, less risk of iatrogenic injury to the marginal mandibular nerve, avoidance of an external scar, minimal risk of postoperative mucocele formation, or inflammation of Wharton's duct ${ }^{11}$.

Preuss et al retrospectively analyzed 258 patients treated with excision of the submandibular gland through intraoral access and found a low percentage of complications ${ }^{12}$.

Preservation of gland function with low risk of surgery for the patient should be primary objective in the treatment of sialolithiasis, furthermore in young and healthy patient like in our case.

\section{Conclusion}

In summary, intraoral technique is an excellent treatment of choice for removal of submandibular sialolithwith preservation of the submandibular gland. As in this present case described here, our young patient showed complete resolution of the symptoms, which there were no injury to the lingual nerves as well as in the duct apparatus of the submandibular gland. 


\section{References:}

1. G. Seifert, Diseases of Salivary Glands, Springer, Berlin, Germany, 2000.

2. Iro H, Zenk J, Escudier MP, Nahlieli O, Capaccio P, Katz P, Brown J, McGurk M. Outcome of minimally invasive management of salivary calculi in 4,691 patients. The Laryngoscope. 2009 Feb 1; 119(2):2638.

3. McGurk M, Escudier MP, Brown JE. Modern management of salivary calculi. British Journal of Surgery. 2005 Jan 1; 92(1):107-12.

4. Nahlieli O, Eliav E, Hasson O, Zagury A, Baruchin AM. Pediatric sialolithiasis. Oral Surgery, Oral Medicine, Oral Pathology and Oral Radiology. 2000 Dec 1; 90(6):709-12.

5. Mathew Cherian N, Vichattu SV, Thomas N, Varghese A. Wharton's Duct Sialolith of Unusual Size: A Case Report with a Review of the Literature. Case reports in dentistry. 2014; 2014.

6. Chung KW, Chung HM. Gross anatomy. 6th ed. Lippincott Williams \& Wilkins; 2008.

7. Erdogmus S, Govsa F, Celik S. Anatomic position of the lingual nerve in the mandibular third molar region as potential risk factors for nerve palsy. Journal of Craniofacial Surgery. 2008 Jan 1; 19(1):264-70.

8. Hald J, Andreassen UK. Submandibular gland excision: short-and long-term complications. ORL. 1994; 56(2):87-91.

9. Novotny GM. Submandibular sialolithiasis: transoral excision. The Journal of Otolaryngology. 1989 Dec; 18(7):354-6.

10. Gross BD. Sialolithiasis: diagnosis and treatment. LDA journal. 1979; 37(2):9-13.

11. Hong KH, Kim YK. Intraoral removal of the submandibular gland: a new surgical approach. Otolaryngology—Head and Neck Surgery. 2000 Jun; 122(6):798-802.

12. Preuss SF, Klussmann JP, Wittekindt C, Drebber U, Beutner D, Guntinas-Lichius O. Submandibular gland excision: 15 years of experience. Journal of oral and maxillofacial surgery. 2007 May 1; 65(5):953-7.

13. Lee LT, Wong YK. Pathogenesis and diverse histologic findings of sialolithiasis in minor salivary glands. Journal of Oral and Maxillofacial Surgery. 2010 Feb 1; 68(2):465-70. 